\title{
Laccase: a green catalyst for the biosynthesis of poly-phenols
}

\author{
Jing Su ${ }^{a}$, Jiajia Fu ${ }^{a}$, Qiang Wang ${ }^{a}$, Carla Silva ${ }^{b}$ and Artur Cavaco-Paulo ${ }^{a, b}$ \\ ${ }^{a}$ Key laboratory of Science and Technology of Eco-Textile, Ministry of Education, Jiangnan University, Wuxi, Jiangsu, China; ${ }^{b} \mathrm{Centre}$ of \\ Biological Engineering (CEB), University of Minho, Braga, Portugal
}

\section{ABSTRACT}

Laccases (benzene diol: oxidoreductases, EC 1.10.3.2) are able to catalyze the oxidation of various compounds containing phenolic and aniline structures using dissolved oxygen in water. Laccase structural features and catalytic mechanisms focused on the polymerization of aromatic compounds are reported. A description about the most recent research on the biosynthesis of chemicals and polymers is made. Selected applications of this technology are considered as well as the advantages, shortcomings and future needs related with the use of laccases.

\section{ARTICLE HISTORY}

Received 22 November 2016 Revised 16 January 2017

Accepted 17 May 2017

\section{KEYWORDS}

Laccase; oxidoreductase; oxidation; polymerization; phenolic

\section{Introduction}

Laccases (EC1.10.3.2) are a family of multi-copper containing oxidoreductases enzymes which are able to catalyze the oxidation of various aromatic compounds with the reduction of molecular oxygen to water [1]. During the process it produces the only byproductwater using air oxygen in a catalytic cycle during which four substrate molecules are oxidized. The fact that laccase can use dissolved oxygen as an oxidative source has led to intensive research. Laccases are probably one of the most promiscuous enzymes since they can catalyze a wide range of substrates, and have gathered much attention for polymer synthesis due to their efficiency in mild reaction conditions [2].

The first discovery of laccases dates back to 1883 based on the observation of rapid hardening of latex from Japanese lacquer trees in the presence of air [3-5], and it was named after isolation and purification $[6,7]$. Since then, laccase activity has been found in other plants species (e.g. mango, mung bean, peach), certain prokaryotes (e.g. Azospirillum lipoferum) and various insects, with the most biotechnologically useful laccases being predominantly of fungal origin (e.g. Ascomycetes, Deuteromycetes, Basidiomycetes) [8-11]. White-rot fungi from Basidiomycetes are the highest producers of laccases. Laccases in fungi carry out a variety of physiological roles including morphogenesis, fungal plantpathogen interaction, stress defense, and lignin degradation $[12,13]$. Since laccases have been found in higher plants, prokaryotes, insects, fungi and lichens [14], such widespread detection indicates that the laccase redox process is ubiquitous in nature.

Over the past decades, oxidoreductases have attracted the efforts of many researchers in the environmental and biotechnological fields because of their great potential to be alternative catalysts to the conventional chemical synthetic processes with no hazardous side effects [15]. Normal chemical-catalyzed reactions can lead to irreversible destruction of the desired substructures and the formation of unwanted by-products. In this regard, laccases have emerged as important enzymes as they are not only eco-friendly but they also work under mild conditions.

Laccases have received attention in biotechnological processes due to their catalytic and electro-catalytic properties, including food, textile, cosmetics, medicine and nanobiotechnology industries. Application areas of laccases are increasing mainly because of their wide substrates range. Laccases catalyze direct oxidation of ortho- and para-diphenols, aminophenols, polyphenols, polyamines, and aryl diamines as well as a few inorganic ions $[12,13,16]$. Some substrates cannot be oxidized solely because of their steric hindrance or the high redox potential, but they can be oxidized by small laccase-radicalized mediators.

Polymer synthesis by laccases has been reviewed by different researchers highlighting this ability [10,17-22]. 
Laccase-catalyzed polymerization of phenols and their various derivatives can give rise to complex polymeric structures. Moreover, during organic synthesis, laccasecatalyzed polymerization has a number of selective and efficient reactions based on various substrates, leading to different polymers. Laccases show excellent biochemical properties and provide a unique alternative to organic synthesis. This article reviews the current knowledge on laccase structure, associated catalytic mechanisms and applications as a green catalyst. It focuses on some emerging trends of laccase applications, highlighting the polymer synthesis.

\section{Laccase catalytic mechanism and properties}

Laccases are glycoproteins which often occur as isoenzymes that oligomerize to form multimeric complexes. The molecular weight of the monomer ranges from 50 to $130 \mathrm{kDa}$. The carbohydrate moiety of laccases which consists of mannose, acetylglucosamine, and galactose, ranges from 10 to $45 \%$ of the protein mass. This carbohydrate moiety is believed to be responsible for the stability of the enzyme.

Laccases catalyze four-electron substrate oxidations, resulting in reductive cleavage of a dioxygen bond. $\mathrm{Cu}$ metal atoms, within the enzymes, play a key role in the reduction of $\mathrm{O}_{2}$ to $\mathrm{H}_{2} \mathrm{O}$. The $\mathrm{Cu}$ atoms of laccases include one copper of type $1\left(\mathrm{Cu}_{1}\right)$, one of type $2\left(\mathrm{Cu}_{2}\right)$ and two of type $3\left(\mathrm{Cu}_{3}\right)$ (Figure 1).

In the laccase-catalyzed oxidation process $\mathrm{Cu}_{1}$ is the primary electron acceptor. The electrons are next transferred via a highly conserved His-Cys-His tripeptide to a tri-nuclear cluster (TNC) which includes $\mathrm{Cu}_{2}$ and $\mathrm{Cu}_{3}$ atoms. Then electrons reduce $\mathrm{O}_{2}$ to $\mathrm{H}_{2} \mathrm{O}[17,24]$. Since $\mathrm{Cu}_{1}$ has a wide cavity on the enzyme surface, a large range of substrates can be accommodated. $\mathrm{Cu}_{1}$ plays the role of a door that offers entry for a substrate

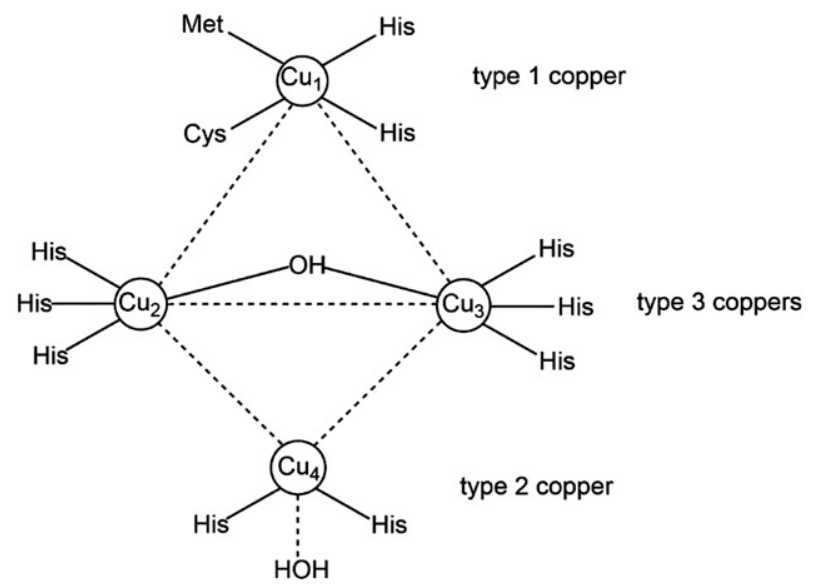

Figure 1. Active site of laccase $\operatorname{Cot} A$ from Bacillus subtilis (adapted from Enguita et al. [23]). electron to the catalytic site. Meanwhile, $\mathrm{Cu}_{1}$ controls the catalytic rate, during the whole catalytic process reduction of $\mathrm{Cu}_{1}$ is rate-limiting [12,25]. The redox potential of $\mathrm{Cu}_{1}$ is relatively low allowing electron abstraction [26-28]. With the four "electrons" transferred from $\mathrm{Cu}_{1}$, the two $\mathrm{Cu}_{2} / \mathrm{Cu}_{3}$ ions arranged in a triangular manner, facilitate dioxygen binding, leading to reduction of molecular oxygen $[12,17]$.

Generally, laccases catalyze phenolic substrates, which loose one electron and one proton and form phenoxy radicals that are stablished by resonance into the respective quinone structures or covalently coupled to oligo- or polymeric products. It has been described that laccases can promote homo- or hetero-molecular coupling reactions. During reactions between phenols or quinonoid systems and primary amines, new $\mathrm{C}-\mathrm{O}$, $\mathrm{C}-\mathrm{N}$ or $\mathrm{N}-\mathrm{N}$ products are formed. Aromatic amines have been mainly used as nucleophiles in phenol reactions catalyzed by laccases [29]. Recently, aromatic amines used as substrates of laccase were described in the oligomerization of aniline to produce conducting polyaniline or in the polymerization of aniline derivatives [30].

Oxidation of phenolic substrates with laccase is summarized in Figure 2(a,b). Enzymatic reactions will be much greener if substrates are natural since laccase catalysts are also natural. In recent research, laccase applications in synthetic chemistry, based on phenols, have trended to mimic natural anabolism, predicting the role that laccases and phenols play during in vivo anabolic processes [17,31]. Naturally occurring phenols used in the synthetic reactions are considered the key substrates of laccase, and the synthetic path seems to be limited to oxidative coupling of natural phenols per se or their cross-coupling into preformed biomacromolecules (Figure 3).

Normally, laccase catalytic properties can be attributed to the following three major steps: (i) T1 copper is reduced by accepting electrons from the reducing substrate; (ii) Electrons are transferred from $\mathrm{T} 1$ copper to the tri-nuclear T2/T3 cluster; (iii) Molecular oxygen is activated and reduced to water at the tri-nuclear T2/T3 cluster. As can be seen in Figure 4(a), the catalytic mechanism of laccase involves a four-electron reduction of the dioxygen molecule to water at the enzyme copper sites $[21,29]$. Oxygen molecule interacts with the completely reduced trinuclear cluster (T2/T3) via a 2eprocess $(\mathrm{k} \approx 2 \times 106 \mathrm{M}-1 \mathrm{~s}-1)$ to produce the peroxide intermediate which contains the dioxygen anion [32]. One oxygen atom of the dioxygen anion is bound to the T2 and T3 copper ions and the other oxygen atom bound to the T3 copper ion. Then, the peroxide intermediate undergoes a second 2e- process ( $>305$ s-1) [33], 
(a)
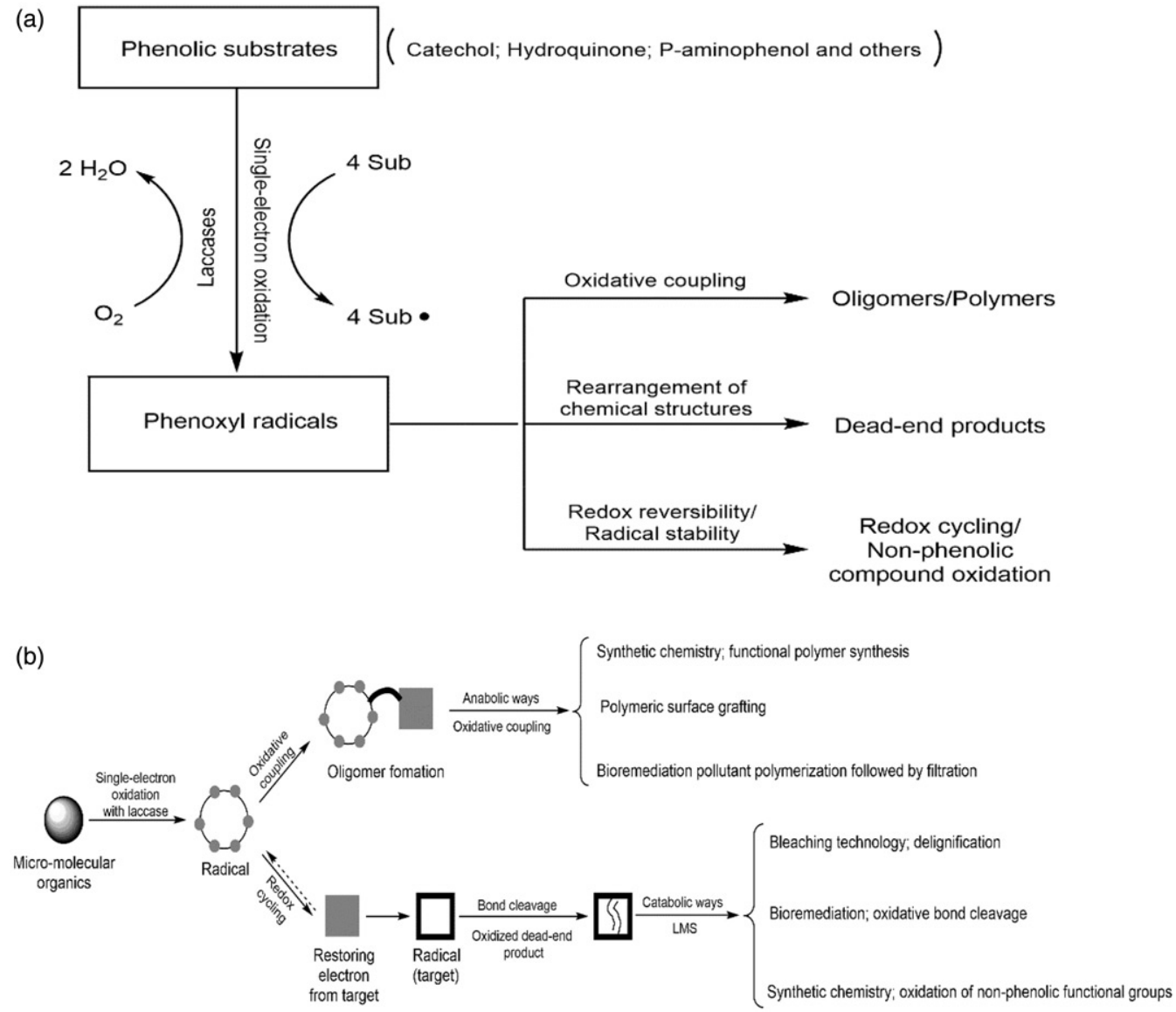

Figure 2. (a) Representative oxidation reactions of phenolic substrates catalyzed by laccase; (b) Bifunctional actions of small organic reactions with laccase (LMS: laccase-mediator system) (adapted from Jeon et al. [18]).

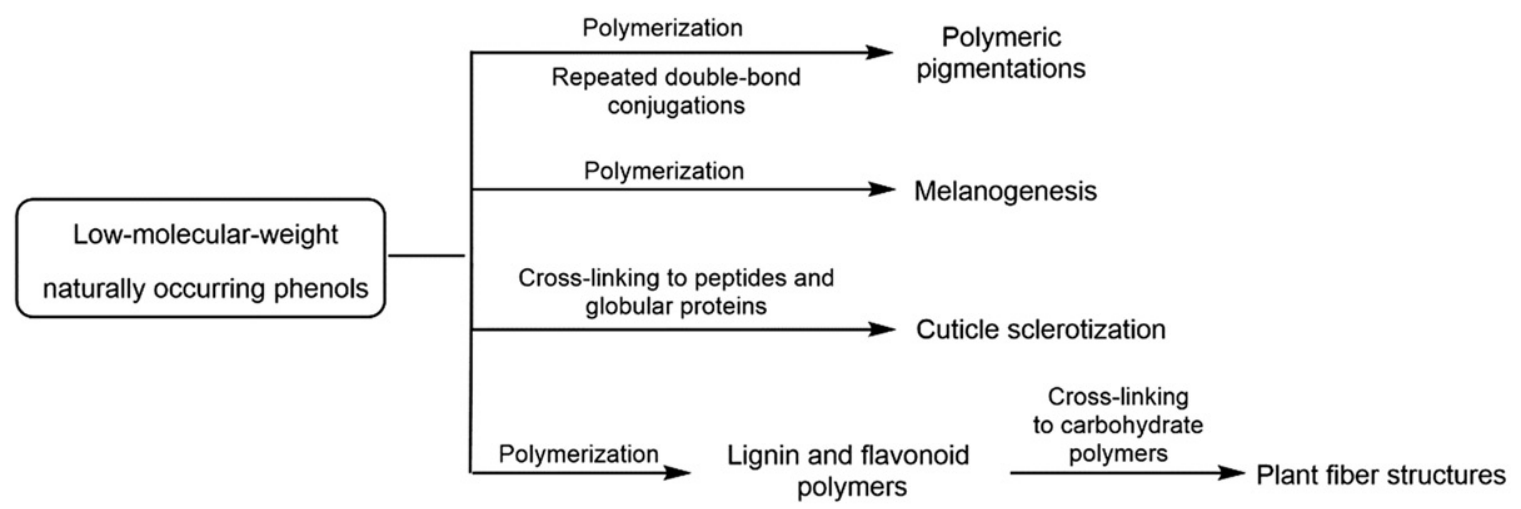

Figure 3. Laccase-catalyzed in vivo anabolic pathways showing the low molecular weight phenol roles played as laccase substrates (adapted from Jeon et al. [18]).

and the peroxide $\mathrm{O}-\mathrm{O}$ bond is split to produce a native intermediate which is a fully oxidized form with the three copper centers in the trinuclear site mutually bridged by the product of full $\mathrm{O}_{2}$ reduction with at least one $\mathrm{Cu}-\mathrm{Cu}$ distance of $3.3 \AA$. This native intermediate form of laccase was confirmed by X-ray spectroscopy (XAS) and magnetic circular dichroism (MCD) by Solomon et al. [34]. Furthermore, it has been proved via model studies and calculations that the three copper centers in the trinuclear cluster are all bridged by a $\mu 3-$ oxo ligand [35]. This structure has a single $\mu 3$-oxo bridged trinuclear CU(II) complex at the center of the cluster, with the second oxygen atom from $\mathrm{O}_{2}$ either remaining bound or dissociated from the trinuclear site as shown in the native intermediate structure in Figure 4(b). This $\mu 3$-oxo bridged structure of the native 


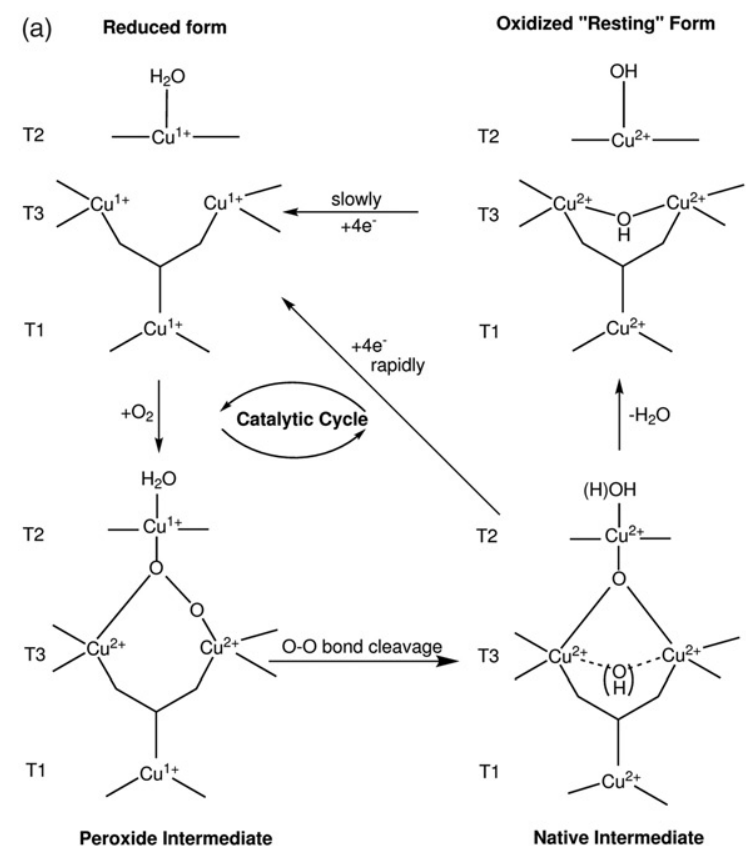

(b)

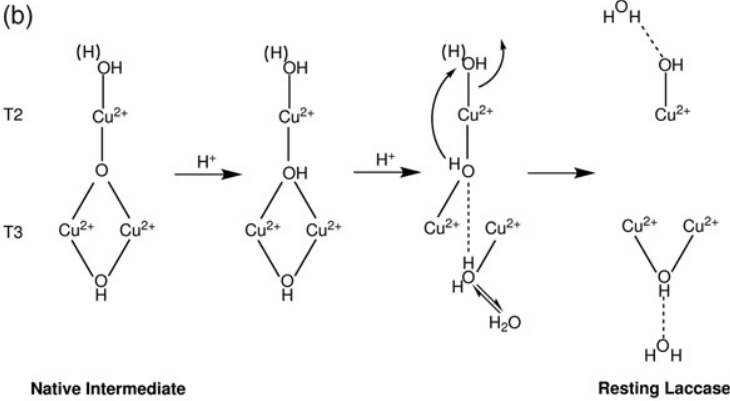

of laccase. The slow decay of the native intermediate is due to the rearrangement of the $\mu 3$-oxo-bridge, the rate limiting step, from inside to outside of the cluster. The $\mathrm{T} 1$ site of this resting laccase can be reduced by a substrate. However, the electron-transfer rate onto the trinuclear cluster (T2/T3) is too low to be significant for catalysis $[34,37]$.

\section{Laccase substrates}

Laccases can catalyze the oxidation of a variety of compounds, including polyphenols, amino-phenols, polyamines, lignin, aryl diamines, and a number of inorganic ions (Figure 5) [18,38]. To accomplish this, laccase abstracts an electron from a substrate to produce a free radical, and reduces oxygen to water, as seen in Figure $6(a)$. The simplified scheme of laccase-catalyzed oxidation is illustrated in Figure 6(b).

Phenol groups are considered typical laccase substrates due to their low redox potentials (see Table 1 for redox potential of different laccase substrates). Phenols are oxidized to phenoxyl free radicals by couplingbased polymerization or radical rearrangement per se, yielding dead end products. However, depending on phenoxyl radical stability, reversibility of the oxidation may be observed; such reactions use the phenolic substrates as laccase mediators [28]. Radical-based coupling or redox recycling of phenolic substrates improves the versatility of laccase catalytic action because non-laccase substrates can serve as oxidation targets.

Phenoxyl radicals are coupled with non-laccase substrates, thus allowing for formation of new heteromolecular dimers. Otherwise, the phenoxyl radicals feature restored $\mathrm{PhOH}$ bonds, resulting from the cleavage of benzylic $\mathrm{C}-\mathrm{H}$ bonds of oxidation targets. Such hydrogen atom transfer oxidation, involving phenolic compounds, gives non-laccase substrates the properties of reactive radicals, finally leading to various types of enzymatic biotransformations. The nonspecific nature of oxidation performed by laccases, combined with the use of enzyme immobilization technology, has encouraged the use of the enzymes in green organic synthesis $[2,10,31,42]$.

During phenol polymerization reactions with laccases, aromatic amines have been mainly used as nucleophiles (Figure 7). The coupling of a typical substrate of laccase, for example, a substituted hydroquinone with primary amines usually occurs as nucleophilic amination on the aromatic ring by the substitution of hydrogen, halides or alkyl groups. Elongation of the reaction time, the increase of reaction temperatures or the reactions with excess of amine, will promote the formation of diaminated products $[25,29]$. 
<smiles>O=C(O)c1cc(O)c(O)c(O)c1</smiles>

(e)<smiles>COc1cc(C(=O)O)cc(OC)c1O</smiles>

(i)<smiles>O=C(O)/C=C/c1ccc(O)cc1</smiles><smiles>Oc1ccc(/C=C/c2cc(O)cc(O)c2)cc1</smiles>

(b)<smiles>C=C(O)/C=C/c1ccc(O)c(OC)c1</smiles>

(f)<smiles>Oc1cc(O)c2c(c1)OC1=C(c3ccc(O)c(O)c3)[C@@H](C[C@H]1O)O2</smiles>

(j)

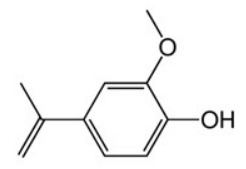

(n)<smiles>COc1cc(/C=C/CO)ccc1O</smiles>

(c)<smiles>Oc1ccccc1O</smiles>

(g)<smiles>COc1cc(C=O)cc(OC)c1O</smiles>

(k)<smiles>COc1cc(C(C)=O)ccc1O</smiles>

(o)

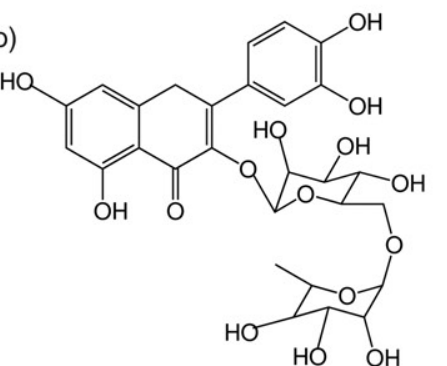

(d)<smiles>On1nnc2ccccc21</smiles>

(h)<smiles>O=C1NC(=O)C(=NO)C(=O)N1</smiles>

(l)<smiles>COc1cc(C(C)=O)cc(OC)c1O</smiles>

(p)<smiles>Cc1cc(O)cc(C)c1O</smiles>

Figure 5. Chemical structures of small organics used for laccase bifunctionality: (a) gallic acid, (b) ferulic acid, (c) catechol, (d) 1-hydroxybenzotriazole, (e) syringic acid, (f) catechin, (g) syringaldehyde, (h) violuric acid, (i) p-coumaric acid, (j) vanillin, (k) acetovanillone, (I) acetosyringone, (m) resveratrol, (n) coniferyl alcohol, (o) rutin, (p) 2,6-dimethoxy-1,4-benzohydroquinone (adapted from Jeon et al. [18]).

(a) $\mathrm{H}_{2} \mathrm{O}$

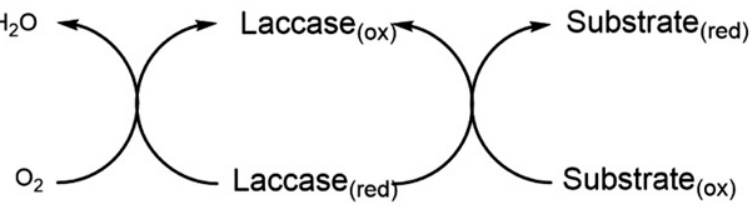

(b)

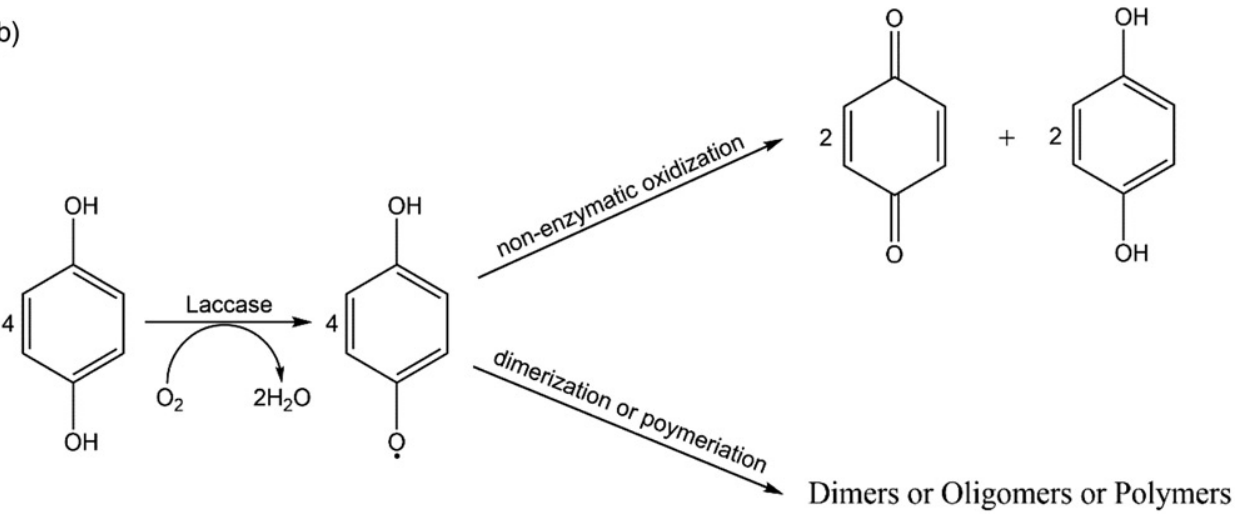

Figure 6. (a) Scheme of laccase-catalyzed redox cycles for substrate oxidation; (b) oxidation of hydroquinone by laccase. 
Table 1. Redox potential (mV) of different laccase substrates.

\begin{tabular}{lr}
\hline Laccase substrate & Redox potential (mV) \\
\hline 2,2-Azino-bis(3ethylbenzthiazoline-6-sulfonic acid) - ABTS & 680 (vs. NHE) [39] \\
1-Hydroxybenzotriazole - HBT & 1080 (vs. SHE) [40] \\
Syringaldazine & 270 (vs. SCE) [41] \\
Promazine - PZ & 540 (vs. SCE) [41] \\
Hydroquinone & 170 (vs. SCE) [41] \\
\hline
\end{tabular}

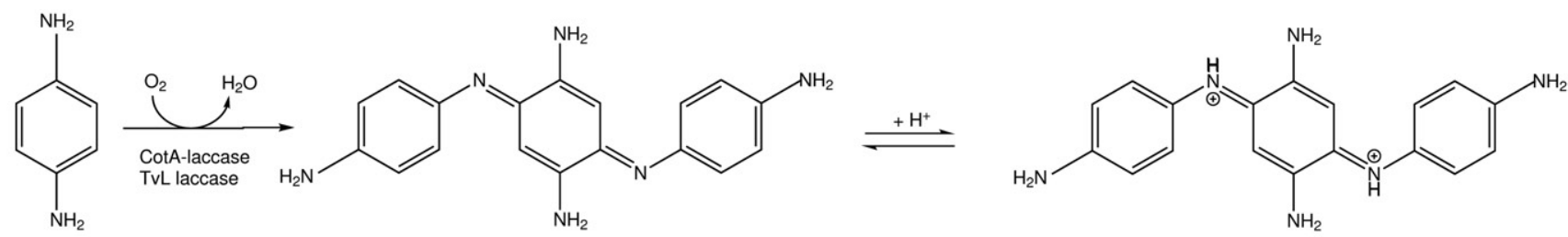

p-aminophenol

intermediate aminated product

Figure 7. Scheme of p-aminophenol polymerization reaction with laccase using amines as nucleophiles.

Oxidation of phenol compounds in the crude extract of the residual compost of Agaricus bisporus using laccase was studied by Trejo-Hernandez et al. [43]. Phenol, guaiacol, 2,6-dimethoxyphenol were oxidized to insoluble products and ventril alcohol was transformed to a soluble aldehyde [43,44]. The relative activity of the compost extract was measured in terms of the time required to oxidize the substrates 2,6-dimethoxyphenol, guaiacol, phenol, ventril alcohol, and aniline.

Monolignols are phytochemicals acting as source materials for the biosynthesis of both lignans and lignin. The laccase-catalyzed oxidation reactions of main monolignols including coniferyl alcohol, isoeugenol and ferulic acid were studied by Chen and his coworkers. Coniferyl alcohol and isoeugenol were oxidized with laccase from Rhus vernicifera (a tree) and Pycnoporus coccineus (a fungus) in acetone water $(1: 1, \mathrm{v} / \mathrm{v})[2,44,45]$. These oxidations followed a first order rate law. The catalytic oxidation rate of isoeugenol and coniferyl alcohol was compared between laccases, and it was found that Pycnoporus laccase-catalyzed oxidation is three to seven times faster than Rhus vernicifera laccase-catalyzed oxidation. As shown in Figure 8(a) both the monolignol and the laccase influence the rate of oxidation.

The transformation of ferulic acid was examined by Nishida and Fukuzumi [46]. The white rot fungus, Trametes versicolor, was cultivated in a medium including ferulic acid, glucose and ethanol under aerobic conditions in a submerged culture. The ferulic acid was transformed into coniferyl alcohol, coniferylaldehyde, dihydroconiferyl alcohol, vanillic acid, vanillyl alcohol, 2-methoxyhydroquinone and 2-methoxyquinone. The biotransformation of ferulic acid in cultures of the white-rot fungus Pycnoporus cinnabarinus 1-937 was also studied by Falconnier and coworkers [47].
When produced, the enzyme countered the vanillin formation by promoting the polymerization of ferulic acid into lignin-like polymers (Figure 8(b)).

The oxidation of ferulic acid by laccase to synthesize phenolic colorants was also investigated [48]. Mustafa and coworkers found that this kind of oxidation in a biphasic hydro-organic system (perfectly mixed) composed of ethyl acetate and sodium-phosphate buffer could result in intermediate stable yellow products. These products could be solved in an organic solvent which decreased the activity of laccase and the rate of non-enzymatic reactions, thus preventing the further polymerization of the intermediate. It was suggested that this yellow-colored products could be applied as food colorants.

As the largest group of colorants, azo dyes have excellent coloring properties and can be oxidized by laccase [49]. Laccase from Pyricularia oryzae was used for the oxidation of phenolic azo dyes. Renganathan and Chivukula [49] found that the azo dyes can be oxidized to 4-sulfonylhydroperoxide, a quinone compound, and other products. During the laccase oxidation phenoxy radicals were formed which were further oxidized into a quinone and 4-sulfonylhydroperoxide. It suggested that laccase oxidation can result in the detoxification of azo dyes.

Aromatic amines used as laccase substrates are described in the oligomerization of aniline to produce conducting polyaniline or polymers of aniline derivatives. 1,4-Phenylenediamine and 4-aminophenol are widely used as dye precursors or oxidation-based compounds for the dyeing of hair. These substrates produce colored compounds as hair dyes, which are of great interest because of healthy demands for direct contact with the human skin. Laccases are thought to be 
(a)
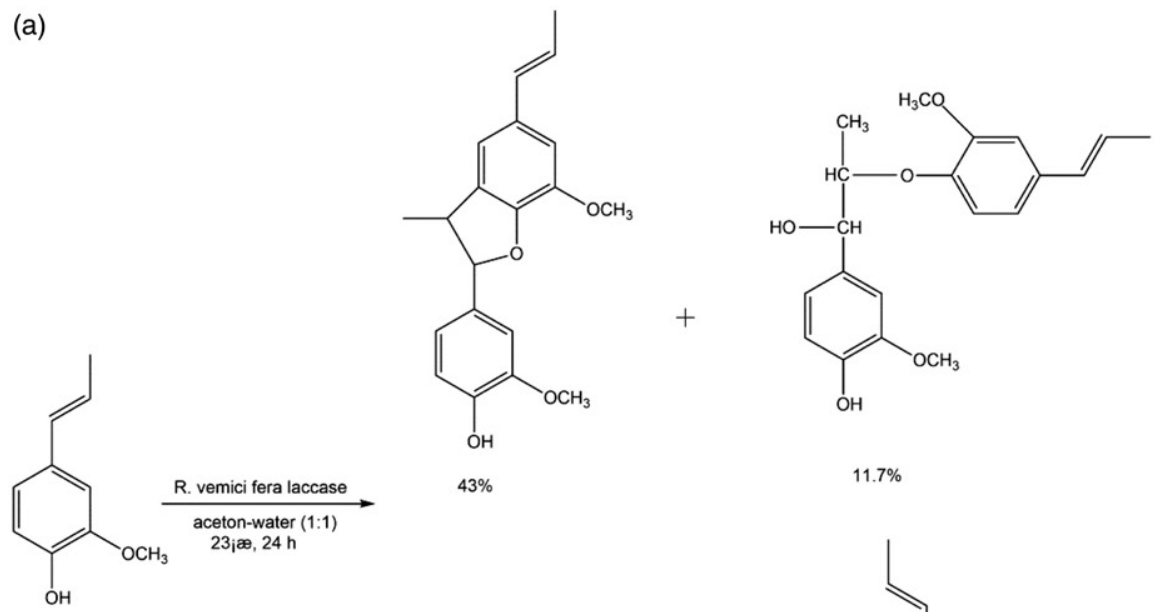

$43 \%$

$11.7 \%$

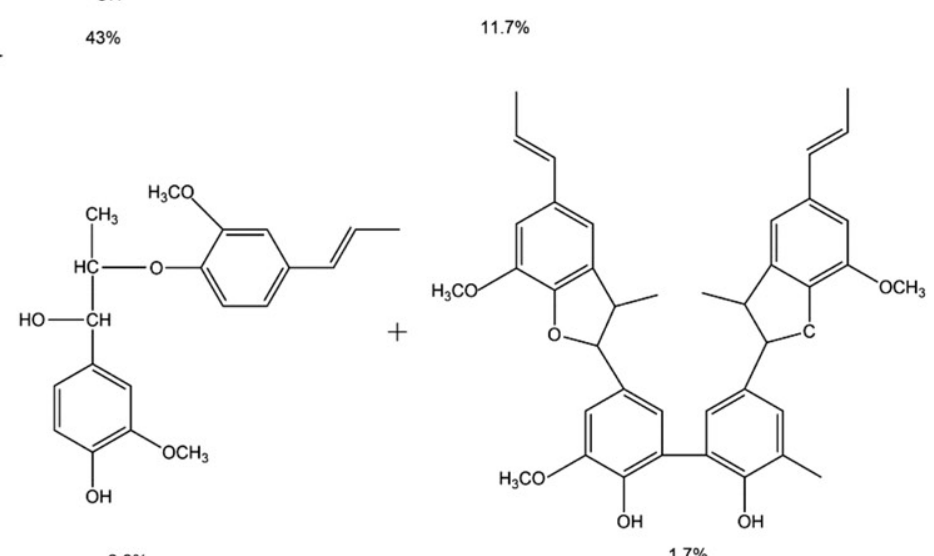

(b)

Ferulic acid

$3.3 \%$

(c)

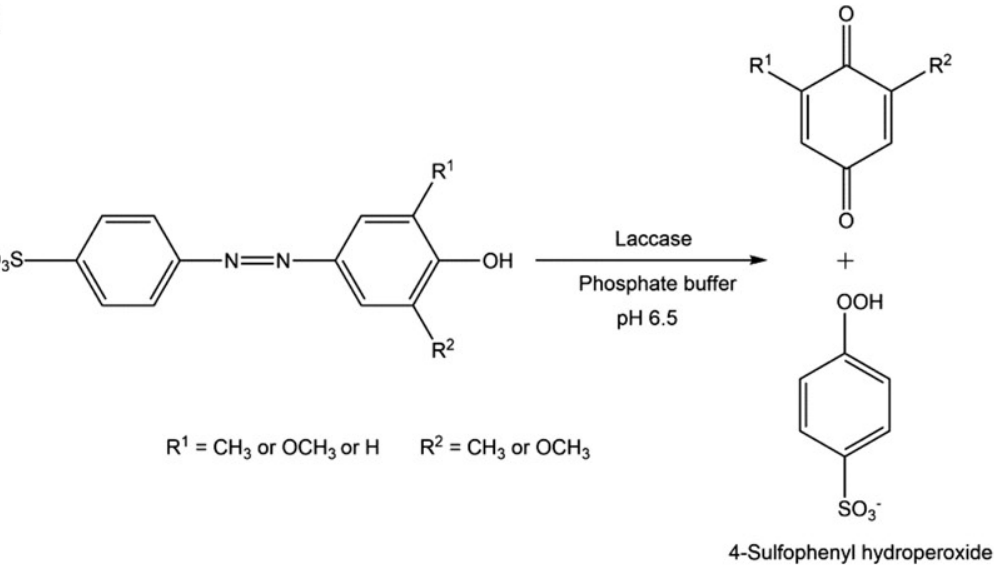

Figure 8. (a) Dimer and tetramer products resulting from the oxidation of isoeugenol alcohol by laccase (adapted from Witayakran [2]). (b) Biotransformation of ferulic acid by laccase (c) The oxidation of phenolic azo dyes by laccase. 


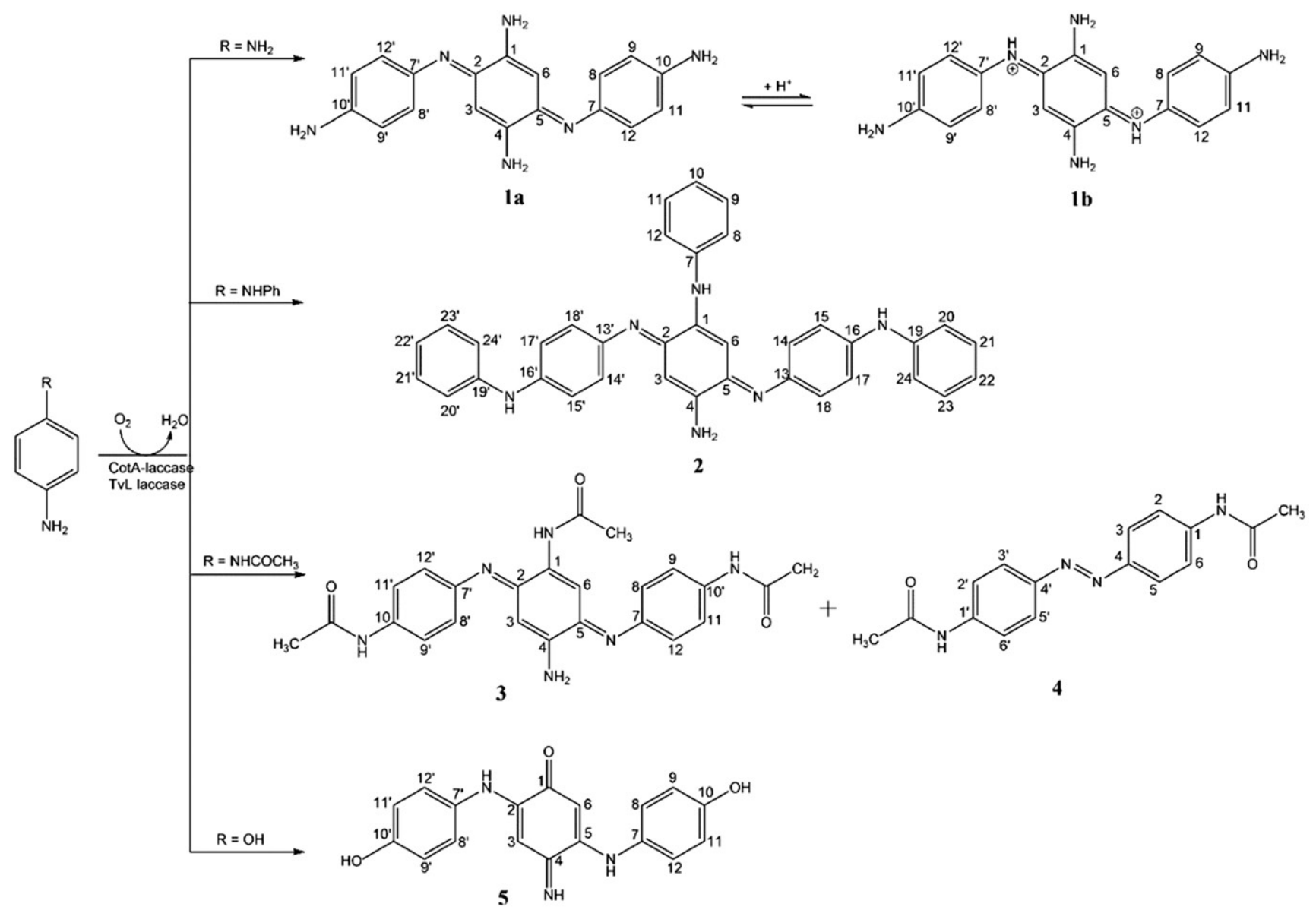

Figure 9. Structures of the main products formed in laccase reactions with $p$-substituted aromatic amines; $(1,2,3)$ : the aromatic nature of benzoquinonediiminic structures; (4): enzymatic oxidized 4-APA intermediate; (5): 2,5-diaminated 1,4-quinonemonoiminic structure.

excellent candidates for the production of biological colorants under mild conditions [50].

The oxidation of 1,4-PDA, 4-ADA and 4-APA results in the formation of trimers with a 1,4-substituted-2,5-benzoquinonediimine skeleton (1-3, Figure 9). The oxidation of 4-AP, with a hydroxyl group results in the formation of the trimeric structure 5, with a 1,4-benzoquinonemonoimine skeleton substituted at positions 2 and 5. The aromatic nature of benzoquinonediiminic structures (1,2 and 3) was confirmed by the presence of multiple signals in the range $5.5-7.8 \mathrm{ppm}$ and 90-160 ppm in both ${ }^{1} \mathrm{H}$ and ${ }^{13} \mathrm{C}$ NMR spectra, respectively [29].

The oxidation product of 1,4-PDA, the trimer 1,4-diamino-2,5-benzoquinonediimine [1] was isolated in two forms $1 \mathrm{a}$ and $1 \mathrm{~b}$ (Figure 9), showing distinct colors (orange and dark purple, respectively) and distinct water solubility. The oxidation of 4-AP leads to formation of a brown solid [5] with a 2,5-diaminated 1,4-quinonemonoiminic structure. The presence of the hydroxy group on $\mathrm{C}-1$, from which a quinonic structure could be easily obtained, should be the responsible for the formation of the 1,4-benzoquinonemonoimine skeleton. This trimeric structure is different from the one reported before for 4-AP oxidation, leading to the formation of the 1,4-substituted-2,5-benzoquinonediimine trimer [51].

Figure 10 shows the proposed pathway that leads to the formation of the disubstituted benzoquinonediimine trimers. The initial step of the laccase oxidation process should be the electron abstraction followed by deprotonation of the substrate. The end products are expected to be two short-lived intermediates: an aminium cation radical $\left(A^{+}\right)$or a neutral radical species $\left(A^{\cdot}\right)$, the aminyl radical, in keeping with species previously detected during laccase oxidation of 1,4-PDA by ferricyanide [52] and as intermediates of the amines oxidation by cytochrome P450 enzyme [53]. Thus, electron-donor substituents in the p-position, by stabilizing the radical cation, are expected to lower the transition state energy and speed up the enzymatic oxidation, whereas electron-withdrawing substituents do retard it.

Therefore, starting from the radical intermediates, which are also susceptible to sequential self-conjugation, 

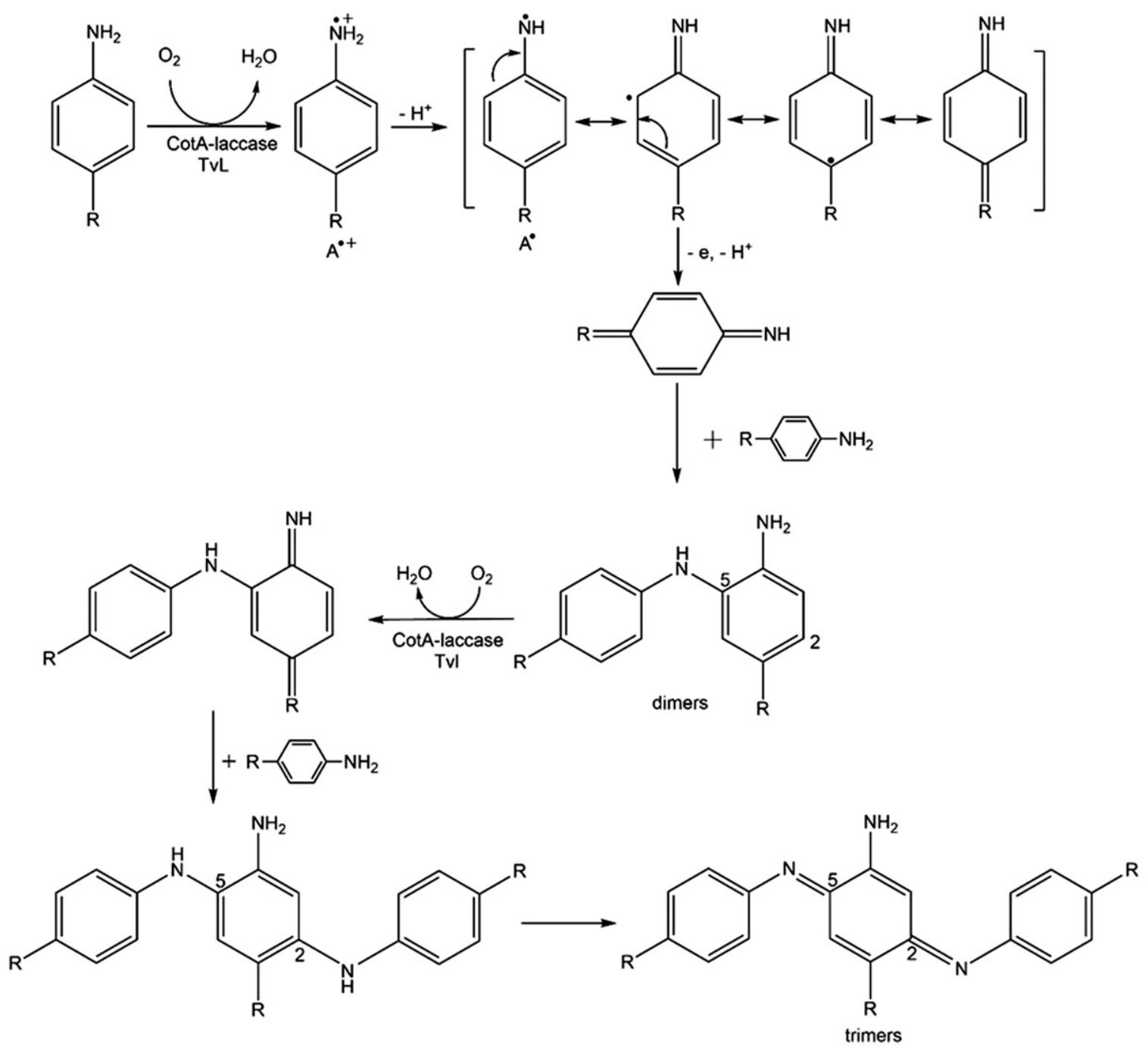

Figure 10. A proposed oxidative pathway for the formation of the disubstituted benzoquinonediimine trimers from laccase and aromatic amines (adapted from Sousa et al., [28]).

the reaction proceeds through the formation of the benzoquinonediimine intermediate and $\mathrm{NC}$ coupling in the activated ortho position (C-5) to the amino group to form a homo molecular dimeric structure. After the first coupling, the second addition on the aromatic ring will occur in the para position ( $\mathrm{C}-2)$ relative to the first covalent $\mathrm{CN}$ bond site and the central ring is stabilized by resonance [29].

According to this pathway, the stability of the radicals seems to be of great importance for the efficiency and the presence of electron-donating substituents on the aromatic ring are considered to be a key factor for this stability.

Considering the electrochemical studies of substrates, difference in the redox potential between oxidoreductases and substrates plays an important role in enzymatic reactions, which influence if the reaction can occur and how fast the reaction proceeds. The aromatic amines can be divided into $p$-electron-donor groups

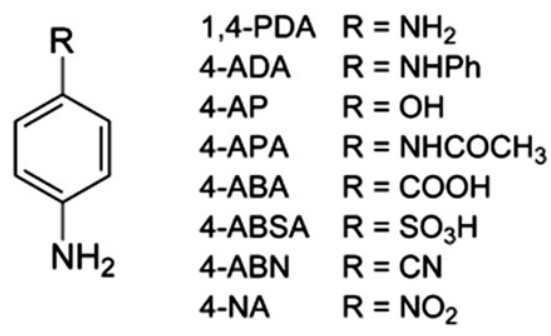

Figure 11. Representative structures of $p$-substituted aromatic amines.

(1,4-PDA, 4-ADA, 4-AP, 4-APA) and $p$-electron-withdrawing groups (4-ABA, 4-ABSA, 4-ABN, 4-NA) [29], of which compounds with only $p$-electron-donor groups can be oxidized by laccase enzymes because $p$-electron-donor group converts recalcitrant amine molecules into laccase substrates by increasing the electronic density on the amine group (Figure 11). 


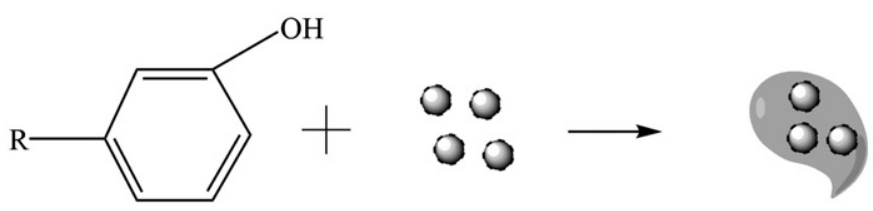

Phenolics

Laccase Laccase 'inside' polymeric products
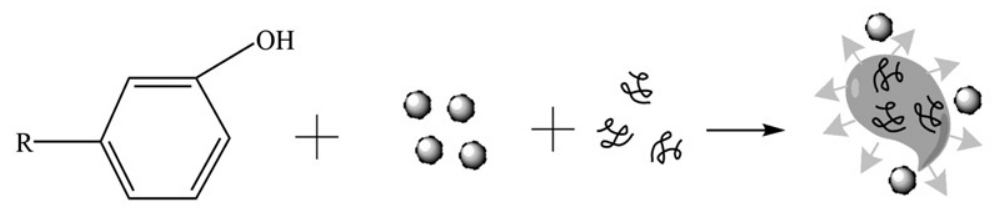

Phenolics

Laccase

PEG

Laccase 'outside' polymeric products

Figure 12. (a) Laccase-based polymerization of phenolic polymers; (b) proposed mechanism for the polymerization using PEG as template.

There are some reports showing that templates were used successfully for controlling the chemical structure of polymers during the polymerization process [54]. These templates promote the formation of the polycatechol and polyaniline, as shown by UV absorption spectroscopy. Studies are related with the use of PEG as a template proposed that interacts with phenol as templates (possibly via $\mathrm{H}$-bonds) which led to the observed regioselectivity in the polymerization reaction [54-57]. It is not exactly clear how the templates enhance the polymerization reaction, whether they interact with substrate and/or only keep polymers soluble $[54,55,57,58]$. PEG is also thought to protect the laccases from being entrapped inside the formed polymer $[59,60]$ (Figure 12).

The use of chemical structure-controlling templates for enzymatic polymerization and the preparation of polymers with a defined chemical structure is still a challenge. Understanding the way template exerts its effect on a molecular level would help on the development and design of new and sustainable polymerization systems [54].

\section{Laccase polymerization of phenolics}

Laccase has been reported to oxidize a variety of phenolic compounds, which would acquire specific functional properties in terms of molecular weight, dispersity, degree of crosslinking, crystallinity, and interand intramolecular bonding [61]. Laccases are able to catalyze the transformation of phenol derivatives through an oxidative coupling reaction, resulting in the formation of less soluble and high molecular weight polymer compounds $[11,28,62]$. The products of laccase-catalyzed oxidation of natural phenols are diverse, ranging from dimers to macromolecules. The properties of such synthesized materials may be further engineered, depending on the type of phenolic monomers used for oligomer and polymer synthesis.

Recent developments about laccase-based synthetic applications have shown that the mimicking of laccasedependent in vivo phenolic anabolism can offer new opportunities for the development of eco-friendly applications. Novel functional properties imparted by special physical or chemical features of the synthesized materials have been of great interest for biotechnological applications.

Several studies have shown that laccase-catalyzed polymerization of natural phenols, including rutin [21], epigallocatechin gallate and catechin [63], yields antioxidant materials more powerful than the natural monomeric phenols. The fact that such in vitro synthetic processes enhance antioxidant capacity is consistent with the fact that high-molecular-weight natural polyphenols are much stronger antioxidants than low-molecular-weight polyphenols of plants. Natural phenols have the ability to be coupled to well-known antibiotic compounds, to synthesize new drugs, or may be cross-coupled with macro-matrices to functionalize surfaces. Methyl catechol was used in reactions with antibiotics such as ampicillin and cefadroxil, that gave rise to heterodimer coupled products via nuclear amination, but the antibiotic potencies of the resulting derivatives were similar to those of the original antibiotics [42].

\section{Laccase polymerization reactions: practical applications}

Textile dyes occupy an important fraction of chemical industry market. Although consumption of dyes by the textile industry already accounts for two-thirds of the total dyestuff market, recent world dyes and organic pigments industry have estimated a further $3.5 \%$ annual growth for the period 2013-2018 [25]. Due to their 
toxicity and the harsh operative conditions required for their synthesis, this growth has been accompanied by strict legislation regarding removal of dyes from industrial effluents and has encouraged the development of ecofriendly processes for their disposal. In this scenario, laccases have shown to play a pivotal and double role. They are efficient biocatalysts for biodegradation of synthetic dyes and attractive enzymes for coupling reactions leading to the production of novel colored products.

Small colorless aromatic compounds such as phenols, aminophenols and diamines are oxidized by laccase to aryloxy radicals that may undergo further non-enzymatic reactions leading to the formation of colored products. Experimental evidence has shown the ability of laccase to catalyze the formation of colored products (from yellow/brown to red and blue) by oxidation of benzene derivatives containing at least two substituents (comprising amino, hydroxyl, and methoxy groups) [64]. Colorful materials are synthesized by coupling reactions resulting in oligomer or polymer synthesis. Chromophore formation is achieved via repetitive double-bond conjugation $[1,65,66]$.

Derivatization of various phenolic and non-phenolic substrates may represent a strategy to expand their range of applications such as bio-coloration. The textile industry is the main area in which bio-coloration has been valuable. Such polymerized flavonoids are generally dark brown, and the extent of coupling to fabric surfaces can be manipulated by varying the $\mathrm{pH}$, the temperature and the extent of mechanical agitation $[1,65]$.

Apart from its application in textile dyeing, enzymatically controlled coloration is relevant in the fields of cosmetic production, owing to the eco-friendly features of the synthesized dyes $[64,66]$. The use of polyphenols from plant fibers in laccase-catalyzed polymerization, yields diverse colors in the visible spectrum, thus allowing a pallet of colors to be precisely formulated.

Traditional chemical-based hair coloring products are often irritant, difficult to handle and unsafe! Hydrogen peroxide $\left(\mathrm{H}_{2} \mathrm{O}_{2}\right)$ and phenylenediamines are the most used chemicals in hair dying. They are allergenic and carcinogenic [67] and can, respectively, cause severe hair damage $[68,69]$. Laccase can act as an alternative oxidizing agent, substituting $\mathrm{H}_{2} \mathrm{O}_{2}$. Laccase-based hair dying is an emerging research field. Deep black colored polymers were achieved after laccase polymerization of catechin and catechol for application in cosmetics for hair coloration $[66,68]$. The authors indicated that the laccase-catalyzed polymerization of natural phenols to produce polymeric hair dyes would be a promising and applicable "green" technology in the cosmetics industry.

In the cosmetic field, increasing interest has also been focused on laccase application in the formulation of some personal hygiene products, including deodorants, toothpaste, mouthwash, and soaps. The importance of these oxidoreductases as efficient catalysts in these fields is underlined by the increasing number of patents registered in the last few years [70]. Samuelson (Patent US 6569651) claims an enzymatic polymerization of anilines or phenols around a template [71]. Barfoed presents the enzymatic method for textile dyeing, where the polymer dyes obtained can be applied with cotton, fur, leather, silk, and wool [72].

Food industry benefits from laccase application in different sectors and for multiple purposes: from modification of food sensory parameters and texture to improvement of products' shelf-life and determination of certain compounds in beverages. In fact, many laccase substrates, mostly phenols, thiol-containing proteins and unsaturated fatty acids are fundamental components of various foods and beverages, thus their modification may lead to new functionalities, quality improvement and cost reductions.

\section{Final remarks}

Laccases are ancient enzymes with promising futures. Since the first laccase-based commercial product, launched in 1996 by Novozyme (Novo Nordisk, Denmark), many companies have been engaged in producing this enzyme in several formulations and for different purposes, mainly for the textile and food industries.

As presented in this review, laccase-assisted reactions have potential for a vast range of applications. Research regarding the modification of natural polymers like lignin and cellulose and their application in wood and paper industries represents an important portion of the applicative research conducted so far using laccases. Other emerging sectors in which laccase has been object of exploitation are bio-sensing and fuel cells, cosmetics, biopolymer synthesis, food and textile industries. The use of laccases as green catalysts for the synthesis of high value-added organic compounds is emerging as a new sector of applicative research, although still poorly exploited.

Despite the plethora of applications, laccase potentialities are not fully exploited, due to several issues related with the costs and enzyme efficiency. Enzyme-producing companies have been directing their efforts to the improvement of enzyme activity and/or stability through immobilization and protein engineering techniques. 
Other stabilization approaches have been also considered, namely, enzyme functionalization, medium engineering, addition of polymers and surfactants, among others.

The applications reviewed herein present laccase as a green alternative to the current physicochemical methods which are environmentally unfriendly, costly and less specific. This class of enzymes is of great relevance both as a model for structure/function relationship studies as well as green tools for biotechnology industries.

\section{Acknowledgements}

This study was supported by Chinese Government Scholarship under China Scholarship Council (No. 201606790036) and Chinese Foundation Key projects of governmental cooperation in international scientific and technological innovation (No. 2016 YFE0115700). The authors would also like to acknowledge Portuguese Foundation for Science and Technology (FCT) for the funding of UID/BIO/04469/2013 unit and COMPETE 2020 (POCl-01-0145-FEDER-006684) and BioTecNorte operation (NORTE-01-0145-FEDER-000004) funded by European Regional Development Fund under the scope of Norte2020 - Programa Operacional Regional do Norte.

\section{Disclosure statement}

No potential conflict of interest was reported by the authors.

\section{Funding}

This study was supported by Chinese Government Scholarship under China Scholarship Council (No. 201606790036) and Chinese Foundation Key projects of governmental cooperation in international scientific and technological innovation (No. 2016 YFE0115700). The authors would also like to acknowledge Portuguese Foundation for Science and Technology (FCT) for the funding of UID/BIO/04469/2013 unit and COMPETE 2020 (POCI-01-0145-FEDER-006684) and BioTecNorte operation (NORTE-01-0145-FEDER-000004) funded by European Regional Development Fund under the scope of Norte2020 - Programa Operacional Regional do Norte.

\section{References}

[1] Kim SY, Zille A, Murkovic M, et al. Enzymatic polymerization on the surface of functionalized cellulose fibers. Enzyme Microb Technol. 2007;40:1782-1787.

[2] Witayakran S, Ragauskas AJ. Synthetic applications of laccase in green chemistry. Adv Synth Catal. 2009;351:1187-1209.

[3] Maciel MJM, Silva ACE, Ribeiro HCT. Industrial and biotechnological applications of ligninolytic enzymes of the basidiomycota: a review. Electronic J Biotechnol. 2010;13:14-15.
[4] Call HP, Mucke I. History, overview and applications of mediated lignolytic systems, especially laccasemediator-systems (Lignozym(R)-process). J Biotechnol. 1997;53:163-202.

[5] Yoshida H. LXIII.-Chemistry of lacquer (Urushi). Part I. Communication from the Chemical Society of Tokio. J Chem Soc Trans. 1883;43:472-486.

[6] Strong PJ, Claus H. Laccase: a review of its past and its future in bioremediation. Critic Rev Environ Sci Technol. 2011;41:373-434.

[7] Fu JJ, Nyanhongo GS, Gubitz GM, et al. Enzymatic colouration with laccase and peroxidases: recent progress. Biocatal Biotransform. 2012;30:125-140.

[8] Baldrian P. Fungal laccases: occurrence and properties. Fems Microbiol Rev. 2006;30:215-242.

[9] Arora DS, Sharma RK. Ligninolytic fungal laccases and their biotechnological applications. Appl Biochem Biotechnol. 2010;160:1760-1788.

[10] Kunamneni A, Camarero S, Garcia-Burgos C, et al. Engineering and applications of fungal laccases for organic synthesis. Microb Cell Fact. 2008;7:32.

[11] Gianfreda L, Xu F, Bollag J-M. Laccases: a useful group of oxidoreductive enzymes. Bioremed J. 1999;3:1-26.

[12] Giardina P, Faraco V, Pezzella C, et al. Laccases: a never-ending story. Cell Mol Life Sci. 2010;67:369-385.

[13] Polak J, Jarosz-Wilkolazka A. Fungal laccases as green catalysts for dye synthesis. Process Biochem. 2012;47: 1295-1307.

[14] Claus H, Decker H. Bacterial tyrosinases. Syst Appl Microbiol. 2006;29:3-14.

[15] Potdar MK, Kelso GF, Schwarz L, et al. Recent developments in chemical synthesis with biocatalysts in ionic liquids. Molecules. 2015;20:16788-16816.

[16] Fairhead M, Thony-Meyer L. Bacterial tyrosinases: old enzymes with new relevance to biotechnology. N Biotechnol. 2012;29:183-191.

[17] Jeon JR, Baldrian P, Murugesan K, et al. Laccase-catalysed oxidations of naturally occurring phenols: from in vivo biosynthetic pathways to green synthetic applications. Microb Biotechnol. 2012;5:318-332.

[18] Jeon J-R, Chang Y-S. Laccase-mediated oxidation of small organics: bifunctional roles for versatile applications. Trends Biotechnol. 2013;31:335-341.

[19] Karamyshev AV, Shleev SV, Koroleva OV, et al. Laccase-catalyzed synthesis of conducting polyaniline. Enzyme Microb Technol. 2003;33:556-564.

[20] Kim S, Silva C, Zille A, et al. Characterisation of enzymatically oxidised lignosulfonates and their application on lignocellulosic fabrics. Polym Int. 2009;58: 863-868.

[21] Kurisawa M, Chung JE, Uyama H, et al. Laccase-catalyzed synthesis and antioxidant property of poly(catechin). Macromol Biosci. 2003;3:758-764.

[22] Mita N, Tawaki S, Uyama H, et al. Structural control in enzymatic oxidative polymerization of phenols with varying the solvent and substituent nature. Chem Lett. 2002;31:402-403.

[23] Enguita FJ, Martins LO, Henriques AO, Carrondo MA Crystal structure of a bacterial endospore coat component. A laccase with enhanced thermostability properties. J Biol Chem. 2003;278:19416-19425. 
[24] Solomon El, Augustine AJ, Yoon J. O(2) reduction to $\mathrm{H}(2) \mathrm{O}$ by the multicopper oxidases. Dalton Trans. 2008;30:3921-3932.

[25] Pezzella C, Guarino L, Piscitelli A. How to enjoy laccases. Cell Mol Life Sci. 2015;72:923-940.

[26] Shleev SV, Morozova O, Nikitina O, et al. Comparison of physico-chemical characteristics of four laccases from different basidiomycetes. Biochimie. 2004;86: 693-703.

[27] Camarero S, Garcia O, Vidal T, et al. Efficient bleaching of non-wood high-quality paper pulp using laccasemediator system. Enzyme Microb Technol. 2004;35: 113-120.

[28] Canas Al, Camarero S. Laccases and their natural mediators: biotechnological tools for sustainable ecofriendly processes. Biotechnol Adv. 2010;28:694-705.

[29] Sousa AC, Martins LO, Robalo MP. Laccase-catalysed homocoupling of primary aromatic amines towards the biosynthesis of dyes. Adv Synth Catal. 2013;355: 2908-2917.

[30] Shumakovich G, Kurova V, Vasileva I, et al. Laccasemediated synthesis of conducting polyaniline. J Mol Catal B-Enzym. 2012;77:105-110.

[31] Riva S. Laccases: blue enzymes for green chemistry. Trends Biotechnol. 2006;24:219-226.

[32] Cole JL, Ballou DP, Solomon El. Spectroscopic characterization of the peroxide intermediate in the reduction of dioxygen catalyzed by the multicopper oxidases. J Am Chem Soc. 1991;113:8544-8546.

[33] Palmer AE, Lee SK, Solomon El. Decay of the peroxide intermediate in laccase: reductive cleavage of the $\mathrm{O}-\mathrm{O}$ bond. J Am Chem Soc. 2001;123:6591-6599.

[34] Lee S-K, George SD, Antholine WE, et al. Nature of the intermediate formed in the reduction of $\mathrm{O}_{2}$ to $\mathrm{H}_{2} \mathrm{O}$ at the trinuclear copper cluster active site in native laccase. J Am Chem Soc. 2002;124:6180-6193.

[35] Mabrouk PA, Orville AM, Lipscomb JD, et al. Variabletemperature variable-field magnetic circular dichroism studies of the iron(II) active site in metapyrocatechase: implications for the molecular mechanism of extradiol dioxygenases. J Am Chem Soc. 1991;113:4053-4061.

[36] Yoon J, Liboiron BD, Sarangi R, et al. The two oxidized forms of the trinuclear $\mathrm{Cu}$ cluster in the multicopper oxidases and mechanism for the decay of the native intermediate. Proc Natl Acad Sci USA. 2007;104: 13609-13614.

[37] Solomon El, Sundaram UM, Machonkin TE. Multicopper oxidases and oxygenases. Chem Rev. 1996;96:2563-2606.

[38] Mayer SF, Kroutil W, Faber K. Enzyme-initiated domino (cascade) reactions. Chem Soc Rev. 2001;30:332-339.

[39] Frasconi M, Favero G, Boer $H$, et al. Kinetic and biochemical properties of high and low redox potential laccases from fungal and plant origin. Biochim Biophys Acta. 2010;1804:899-908.

[40] Xu F, Kulys JJ, Duke K, et al. Redox chemistry in laccase-catalyzed oxidation of n-hydroxy compounds. Appl Environ Microbiol. 2000;66:2052-2056.

[41] Fernandez-Sanchez C, Tzanov T, Gubitz GM, et al. Voltammetric monitoring of laccase-catalysed mediated reactions. Bioelectrochemistry. 2002;58:149-156.
[42] Mikolasch A, Schauer F. Fungal laccases as tools for the synthesis of new hybrid molecules and biomaterials. Appl Microbiol Biotechnol. 2009;82:605-624.

[43] Trejo-Hernandez MR, Lopez-Munguia A, Quintero Ramirez R. Residual compost of Agaricus bisporus as a source of crude laccase for enzymic oxidation of phenolic compounds. Process Biochem. 2001;36: 635-639.

[44] Mai C, Schormann W, Hüttermann A. Chemo-enzymatically induced copolymerization of phenolics with acrylate compounds. Appl Microbiol Biotechnol. 2001;55:177-186.

[45] Shiba T, Xiao L, Miyakoshi T, et al. Oxidation of isoeugenol and coniferyl alcohol catalyzed by laccases isolated from Rhus vernicifera Stokes and Pycnoporus coccineus. J Mol Catal B Enzym. 2000;10:605-615.

[46] Nishida A, Fukuzumi T. Formation of coniferyl alcohol from ferulic acid by the white rot fungus Trametes. Phytochemistry. 1978;17:417-419.

[47] Falconnier B, Lapierre C, Lesage-Meessen L, et al. Vanillin as a product of ferulic acid biotransformation by the white-rot fungus Pycnoporus cinnabarinus I-937: identification of metabolic pathways. J Biotechnol. 1994;37:123-132.

[48] Mustafa R, Muniglia L, Rovel B, et al. Phenolic colorants obtained by enzymatic synthesis using a fungal laccase in a hydro-organic biphasic system. Food Res Int. 2005;38:995-1000.

[49] Chivukula M, Renganathan V. Phenolic azo dye oxidation by laccase from Pyricularia oryzae. Appl Environ Microbiol. 1995;61:4374-4377.

[50] Anderson JS. The chemistry of hair colorants. J Soc Dyers Colour. 2000;116:193-196.

[51] Fenger TH, Bols M. Simple cyclodextrin aldehydes as excellent artificial oxidases. J Incl Phenom Macrocycl Chem. 2011;69:397-402.

[52] d'Acunzo F, Galli C. First evidence of catalytic mediation by phenolic compounds in the laccase-induced oxidation of lignin models. Eur J Biochem. 2003;270: 3634-3640.

[53] Guengerich F, MacDonald T. Mechanisms of cytochrome P-450 catalysis. FASEB J. 1990;4:2453-2459.

[54] Walde P, Guo Z. Enzyme-catalyzed chemical structurecontrolling template polymerization. Soft Matter. 2011;7:316-331.

[55] Kim Y-J, Uyama H, Kobayashi S. Enzymatic template polymerization of phenol in the presence of water-soluble polymers in an aqueous medium. Polym J. 2004;36:992-998.

[56] Kim Y-J, Uyama H, Kobayashi S. Regioselective synthesis of Poly(phenylene) as a complex with Poly(ethylene glycol) by template polymerization of phenol in water. Macromolecules. 2003;36:5058-5060.

[57] Kim Y-J, Uyama H, Kobayashi S. Peroxidase-catalyzed oxidative polymerization of phenol with a nonionic polymer surfactant template in water. Macromol Biosci. 2004;4:497-502.

[58] Kinsley C, Nicell JA. Treatment of aqueous phenol with soybean peroxidase in the presence of polyethylene glycol. Bioresource Technol. 2000;73:139-146.

[59] Modaressi K, Taylor KE, Bewtra JK, et al. Laccase-catalyzed removal of bisphenol-A from water: protective 
effect of PEG on enzyme activity. Water Res. 2005;39:4309-4316.

[60] Bruno FF, Nagarajan R, Kumar J, et al. Novel enzymatic polyethylene oxide-polyphenol system for ionic conductivity. J Macromol Sci Part A. 2002;39:1061-1068.

[61] Aktas N, Kibarer G, Tanyolac A. Effects of reaction conditions on laccase-catalyzed alpha-naphthol polymerization. J Chem Technol Biotechnol. 2000;75:840-846.

[62] Chaurasia PK, Bharati SL, Sharma M, et al. Fungal laccases and their biotechnological significances in the current perspective: a review. COC. 2015;19: 1916-1934.

[63] Snyder SH. Neuroscience at Johns Hopkins. Neuron. 2005;48:201-211.

[64] Shin H, Guebitz G, Cavaco-Paulo A. 'In situ' enzymatically prepared polymers for wool coloration. Macromol Mater Eng. 2001;286:691-694.

[65] Kim S, Lopez C, Guebitz G, et al. Biological coloration of flax fabrics with flavonoids using laccase from Trametes hirsuta. Eng Life Sci. 2008;8:324-330.

[66] Jeon JR, Kim EJ, Murugesan K, et al. Laccasecatalysed polymeric dye synthesis from plant-derived phenols for potential application in hair dyeing: enzymatic colourations driven by homo- or hetero-polymer synthesis. Microb Biotechnol. 2010;3:324-335.

[67] Zhukhlistova NE, Zhukova YN, Lyashenko AV, et al. Three-dimensional organization of three-domain copper oxidases: a review. Crystallogr Rep. 2008;53: 92-109.

[68] Bertrand T, Jolivalt C, Briozzo P, et al. Crystal structure of a four-copper laccase complexed with an arylamine: insights into substrate recognition and correlation with kinetics. Biochemistry. 2002;41:7325-7333.

[69] Piontek K, Antorini M, Choinowski T. Crystal structure of a laccase from the fungus Trametes versicolor at 1.90-A resolution containing a full complement of coppers. J Biol Chem. 2002;277:37663-37669.

[70] Kunamneni A, Plou FJ, Ballesteros A, et al. Laccases and their applications: a patent review. BIOT. 2008;2: 10-24.

[71] Samuelson LA, Tripathy SK, Bruno F, et al. Enzymatic polymerization of anilines or phenols around a template. Google Patents. 2003.

[72] Barfoed M, Kirk O, Salmon S. Enzymatic method for textile dyeing. Google Patents. 2001. 